This item was submitted to Loughborough's Research Repository by the author.

Items in Figshare are protected by copyright, with all rights reserved, unless otherwise indicated.

\title{
The opportunities that different cultural contexts create for sustainable design: a laundry care example
}

\section{PLEASE CITE THE PUBLISHED VERSION}

http://dx.doi.org/10.1016/j.jclepro.2015.04.082

\section{PUBLISHER}

(C) Elsevier Ltd

VERSION

AM (Accepted Manuscript)

\section{PUBLISHER STATEMENT}

This work is made available according to the conditions of the Creative Commons Attribution-NonCommercialNoDerivatives 4.0 International (CC BY-NC-ND 4.0) licence. Full details of this licence are available at: https://creativecommons.org/licenses/by-nc-nd/4.0/

\section{LICENCE}

CC BY-NC-ND 4.0

\section{REPOSITORY RECORD}

Spencer, Jak, Debra Lilley, and Samantha Porter. 2015. "The Opportunities That Different Cultural Contexts Create for Sustainable Design: A Laundry Care Example”. Loughborough University.

https://hdl.handle.net/2134/17633. 


\title{
THE OPPORTUNITIES THAT DIFFERENT CULTURAL CONTEXTS CREATE FOR SUSTAINABLE DESIGN: A LAUNDRY CARE EXAMPLE
}

\author{
Dr Jak Spencer ${ }^{1}$, Dr Debra Lilley², Dr Samantha Porter 3 \\ Sustainable Design Research Group, Loughborough Design School, Loughborough \\ University, Loughborough, LE11 3TU, UK. \\ 1j.a.spencer@lboro.ac.uk, +44 1509223581 \\ 2 d.lilley@lboro.ac.uk, +44 1509222660 \\ 3C.s.porter@lboro.ac.uk, +44 1509222782
}

Word count: 7980

\begin{abstract}
Increasing economic growth coupled with rapidly expanding populations in developing countries has led to the emergence of a large "consumer class". This rapid increase in consumption has altered household consumption behaviour and resource use, often adversely affecting their environmental footprint. There is, therefore, a pressing need to understand the effect culture has on product interactions, particularly when designing new products and systems for emerging markets. This paper presents the findings of an in depth user study which set out to explore the effect of culture on household resource use. In depth, qualitative user research was undertaken into the laundry procedure in three regions. Incontext interviews, observations and household tours were carried out in 19 households across three sites; The East Midlands, UK; Curitiba, Brazil; and Bangalore, India. Findings show significantly different behaviours in washing techniques, routine, consumption patterns and aspirations. The results inform the development of a methodological cultural resource as well as set of 7 design guidelines to understand the effect of designing interventions for sustainable behaviour in different cultural contexts.
\end{abstract}

Keywords: Behaviour, culture, cross-cultural research, sustainable design, laundry care

\section{Introduction}

Over the last half-century the increasing strain on the earth's finite resources has meant that sustainable development has gained increasing prominence in governmental policy around the globe (Jackson, 2009). One of the main causes for this environmental degradation has been the rapid industrialisation of developed countries (Smith, 1997; Green \& Vergragt, 2002).

Traditionally this over-consumption from developed 'Western' economies has been counteracted by 'under-consumption' in developing countries. If everyone lived like the average UK consumer we would require 3.4 planets to support our resource use, whilst in 
India it is just 0.4 planets (Global Footprint Network, 2010). However this imbalance is now changing as large emerging markets, with millions of new consumers, are growing rapidly in developing countries following the 'Western' model of consumption.

Despite efforts to reduce resource consumption through increased technological product efficiencies, household energy use has increased (Tang \& Bhamra, 2012). In recent years, however, there has been a growing research area in design to reduce resource impacts during the use phase of products or services (Lockton et al., 2008; Petterson and Boks, 2008; Lilley, 2009). Until recently however these have tended to focus on research of a single context with limited cross transferability or insight into other contexts. The few projects that have used cross-cultural studies have generated significant insights into the differences of user behaviour; however they have been very exploratory in their nature and left the door open for further studies (see Matsuhashi et al., 2009 and Elizondo, 2012 for examples).

There is a pressing need to understand cultural differences in behaviours, particularly in the context of designing less resource intensive products and services; however this requires a deep-rooted understanding of the social, cultural and personal norms of a region. Culture plays a crucial role in the energy impact of household behaviours; however, it is an area that has been neglected in the research (Shove, 2003; Pakula \& Stamminger, 2010; Laitala et al., 2012). The aim of this research paper is to understand the antecedents of household behaviour and how they can be affected in different cultural contexts. The results enable designers to act on previous design for behaviour change theory outlined by Lilley (2009), Lockton et al. (2008) and Petterson and Boks (2008) to create products which motivate more sustainable behaviours.

In the next section the complex terms of culture and design for sustainable behaviour are introduced with relevance to the research. In section 3 the methods for in-depth user-centred research into laundry behaviours in the UK, Brazil and India are presented. In section 4 the findings from the study are outlined before section 5 discusses how the results have led to the development of a set of cultural factors and a set of guidelines. Finally the paper concludes by discussing the potential application for the research in changing behaviour through design by moderating designs towards desired behaviours.

\section{Theory}

Culture is a divisive term that causes considerable debate amongst academics. Using culture as an explanatory concept can reduce clarity and confuse readers because of the ambiguity of its definition. Understanding anything about human everyday life can be 
described as a cultural research project (Wilhite, 1999). Despite the controversy, the few design studies that have used culture as a source of inspiration have generated varied and insightful results (Wilhite, 2008; Matsuhashi, 2009; Kuijer, 2010; Elizondo, 2012).

A cross-cultural study is one that "explicitly aims to highlight cultural similarities and differences in one or another aspect of everyday life, and use them to open avenues of theoretical enquiry" (Wilhite, 1999; p2). Definitions for the term have been researched extensively in classical anthropology, with common themes emerging such as the importance of symbolic values, shared knowledge, learned behaviour and collective communication (Kroeber \& Kluckhohn, 1952; Geertz, 1973; Banks \& McGee, 1989). Importantly, culture is collective with people living within a defined social environment sharing patterns and perceptions which impact heavily on their attitudes and behaviours (Chau et al., 2002). Although divisive, it is clear that culture and its encompassing terms can be used to inspire designers to new ways of thinking about problem solving, provided a clear definition can be articulated. For this reason culture, in the context of this research, has been defined as: the shared patterns of behaviours, interactions and understanding learned by a collective group of people.

In business and organisational theory one of the main models used to understand people in different cultures is Hofstede's Cultural Dimensions (1980). Hofstede identified 5 values that differ between cultures and can be used to explain the relationship between employees in a global organisation. These values were: the power distance index (acceptance of hierarchy), collectivism/individualism (sense of belonging to the larger group), masculinity (competitiveness and ambition), uncertainty avoidance index (minimising uncertainty), and long-term orientation (short-term or long-term foresight) (Hofstede, 1980).

As the introduction alluded to, technological advancements creating more efficient appliances tend to be nullified by an increase in consumption (Steg \& Vlek, 2009). In reality, individual behaviours can have a far greater effect on household resource consumption than the technological improvements in product efficiencies (Wilson et al., 2010). Similar to culture however, behaviour is a complex topic that spans across many different fields of research. Behaviours around the home are often habitual, formed as part of routines, with little or no cognitive thought beyond the initial completion of the task (Steg \& Vlek, 2009; Goldsmith \& Goldsmith, 2011). Cultural context strongly affects the formation of habits through the definition of internal characteristics (attitudes, values, etc.) and external characteristics (physical constraints, social practices, etc.) (Triandis, 1980). Habits are developed over a long period of time, with social, environmental and contextual influences and are affected by the understanding, motivation and ability of individuals to change their 
actions (Abrahamse et al., 2005; Steg, 2008).

One key factor integral to developing behaviours is personal motivations. Social theorists suggest that an individuals' perceptions of themselves and the others around them will determine their behaviour (Steg \& Vlek, 2009) with consumption patterns fitting into a social order a common feature amongst consumers (Wilk, 2002). Individual choice theorists, however suggest that motivations come from weighing up the greatest benefit from the lowest cost (Steg \& Vlek, 2009). Whilst motivational factors are important, they are not the sole attribute influencing behaviour. An individuals' surroundings; their context and physical environment such as culture, social class, education, climate, geography, public policy, taxes, cost of goods, etc, will also influence behaviour (Stern, 1999).

There are two predominant theories used to understand everyday behaviour in a design context. These theories introduce the idea of either defining the psychological rational antecedent of an individual's behaviour as an actor (behaviour theory), or to define it based on how societal elements create action or practice (social practice theory). Although Shove's Practice Orientated Product Design Manifesto (Shove, 2006) has introduced the idea of practice into the design process, the number of design studies that have used this approach are still fairly limited (Kuijer \& de Jong, 2009; Haines et al., 2012). Shoves definition of design, focused on isolated, individual and non-temporal components is also argued to be a limited and out-dated way of thinking about design, with current thinking focused around the user's relationship with the internal and external factors that impact and define their context of use and experience (Wilson, 2013). Behaviour theory has well defined models with clear applications and limitations whilst practice theory is limited by its broad, ill-defined concept and lack of application in design cases (Wilson, 2013). Therefore, behaviour theory is used as a basis to build upon in this research.

Design for Sustainable Behaviour (DfSB) attempts to introduce design strategies to influence consumer behaviour towards more sustainable action during the use phase of a product (Lilley, 2009). Designers have the opportunity to challenge and affect habit formation through shaping user perception, learning and interaction (Wilson, 2010; Tang \& Bhamra, 2012). Lilley (2009) argues that there is an axis of influence between the user and the product that determines where the power in decision making lies, see Figure 1. At one end the user makes an informed decision to change behaviour based on real-time aural, visual or tactile information or feedback. At the other end of the axis are technology driven solutions that use intelligent technologies to dictate the mode of use entirely. Understanding this axis of influence allows the designer to position an intervention that balances the needs of the user with the nature of the targeted behaviour (Hanratty et al., 2012). Technology driven solutions 
may not require the user to alter their behaviour consciously, whilst putting the user in control may involve building an emotional relationship between the user and the product, helping to reduce product obsolescence and increase longevity (Chapman, 2005). Whilst powerful in their intent, these design intervention strategies can only be effective if the various approaches are correctly matched to users' needs, understanding and motivations (Hanratty et al., 2012).

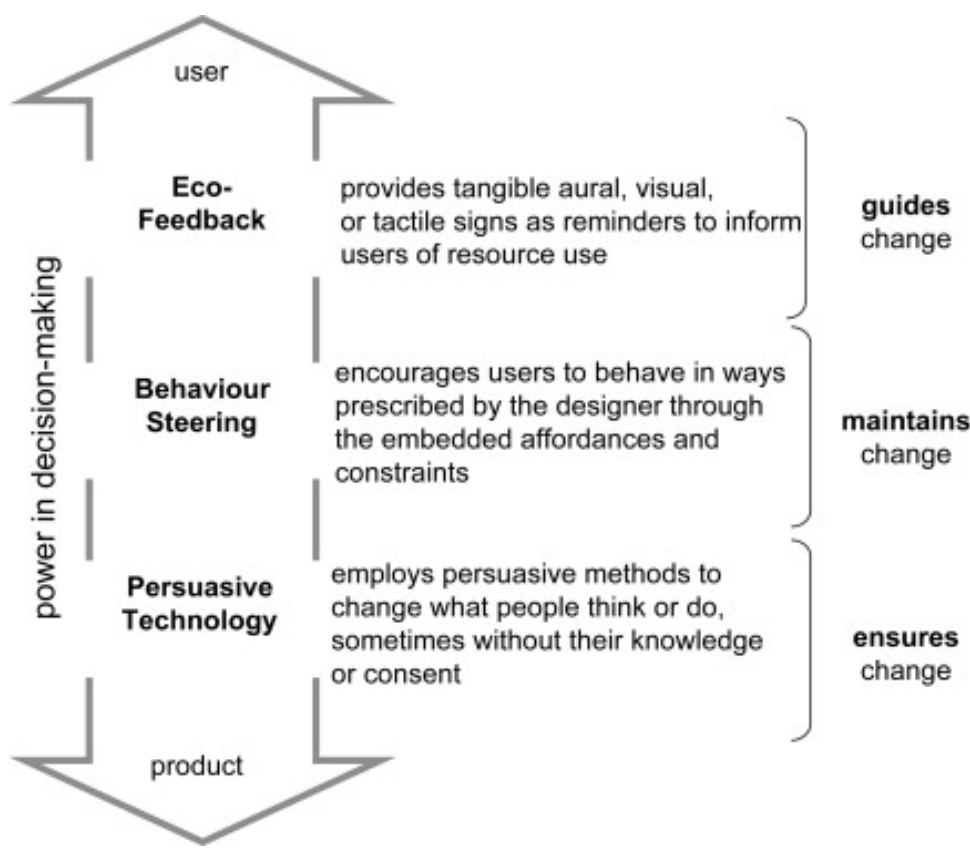

Figure 1: The Axis of Influence between the user and the product (Lilley, 2009)

Lilley's original axis has been considerably built upon over the last five years or so. Lidman et al. (2011) propose a model based on the original axis using the strategies developed by Tang (2010) and Wever et al. (2008) to suggest a classification with five strategy categories along the axis of control: Enlighten, Spur, Steer, Force and Match. Zachrisson et al. (2011) build on the work of Lilley and Tang by identifying a link between the factors that affect a behaviour and the control element of the approaches. Zachrisson suggests that the more control a user has, the more cognitive load the behaviour requires (Zachrisson et al., 2011).

The rapid advancement of theory and growing number of researchers in this relatively new field is testament to the importance of design for sustainable behaviour. However, rather than a direct development of design for sustainable behaviour theory, this research aims to develop a parallel strand of research relating to cultural context, and therefore requires a well established and tested theory to underpin the research. For this reason, Lilley's original model is a useful tool as it has well documented applications and limitations in design studies. 
Laundry and its related topics is an interesting area of study within the research context as it is one of the most widespread household chores in the world and plays an integral part in the everyday logistics of running a house and establishing self-identity (Pink, 2005; Pakula \& Stamminger, 2010). It is a multifaceted process involving more than just cleanliness with social and technical aspects (what needs to be washed, when, what tools need to be used, by whom?) making it a complex household system (Shove, 2003). It can be an incredibly energy intensive form of housework, however working out the exact energy implications is difficult as the system is made up of a huge range of variables influenced by technological, cultural, social and moral norms (Shove, 2003). The age and type of the washing machine affects the energy consumption of the act of laundering as much as the climate of the region or the upbringing of the person doing the laundry (Laitala et al., 2011). Despite huge technological efficiency gains in washing machines, overall energy consumption has increased as consumers have altered the method and frequency of washing and drying (Laitala et al., 2011). Part of this is because energy consumption, particularly when bound up by routine and habit with the use of tools or appliances in a household environment, is simply invisible to the consumer (Shove, 2003). Consumers tend to associate environmental issues with clothing at the end of life; giving it to charity or re-using it, however washing habits and the resource implications vary greatly between cultures with behaviours adjusted to local conditions (Laitala et al., 2011).

Previous research has identified several themes that act as an important base from which to build on. In Shove's study on laundry behaviours, she identified 5 'Whirlpools of Laundering' which help to understand the meanings of doing the laundry including: tools of laundering, when to launder, what to launder, why launder, and how is the laundry done. Other studies by Laitala et al. (2011) and Uitdenbogerd (2007) have revealed a list of sustainable laundry behaviours identified in Table 1 below.

Table 1: Sustainable Laundry Behaviours

\begin{tabular}{|l}
\hline Sustainable Laundry Behaviours: \\
\hline - Wash in cooler water \\
- Use less detergent \\
- Use natural detergent \\
- Control the water and energy levels to suit a particular wash \\
- Line-dry clothes \\
- Fill the machine to the optimum level
\end{tabular}




\section{Methods}

To investigate the opportunities different cultural contexts create for sustainable design indepth user research into laundry behaviours was investigated as this was an area of particular interest identified in previous research.

The research was conducted in three sites; Curitiba, Brazil; Bangalore, India; and Loughborough, UK. The data collected from the study was not designed to draw out statements that were indicative of an entire country or population. Instead, Brazil, India and the UK were chosen as study areas as they show extensively different cultural characteristics with a contrast in levels of economic development and environmental rankings, whilst also having large populations and established or growing markets, highlighting the different contexts that designers often have to design for (Spencer \& Lilley, 2012). The study built upon data from previous quantitative studies (Greendex, 2010; Spencer \& Lilley, 2012) as well as developing themes from specific laundry and cross cultural studies (Shove, 2003; Kuijer \& de Jong, 2009), using well established design research methods.

In terms of laundry facilities, ownership of washing machines in the UK is almost universal (96\%) and 57\% of households own a tumble dryer (ONS, 2011). In Brazil 41.5\% of households own a washing machine, although this figure is growing (IBGE, 2009) and almost all washes are in cold water (Greendex, 2010). In India 14\% of urban and 7\% of rural households own a washing machine; however, rises of 19\% are expected by 2015 (Euromonitor, 2011). Cold water washing is also common (Greendex, 2010).

Curitiba, Bangalore and Loughborough were chosen as study sites for having either an established or emerging consumer class, as well as for practical reasons, with research connections at organisations in all locations. Funding for data collection was provided by the Design Research Society and Santander.

Three data collection techniques were used; contextual observation, household tour (with video), and contextual interview.

Contextual observation and interview are common data collection techniques in qualitative research as they help in collecting information relating to people's behaviours and activities as they occur in real-world settings rather than a controlled environment (McClelland \& Suri, 2005). Interviews were semi-structured around themes identified in the literature (tools, frequency, routine and perceptions).

The household tour allowed the participant to reveal their thoughts regarding artefacts and experiences within their environment whilst the investigator interprets these thoughts 
relevant to the research (Wilson, 2012; Pink, 2005). Walking with the participants in their environment can prompt the participant to reveal their thoughts or actions around certain artefacts or actions that would not have otherwise been apparent using just the interview method (McClelland \& Suri, 2005). One limitation of observation is the potential short term nature of the technique, however video helped to reduce this as Pink states "in the absence of long-term participant observation, video therefore provides alternative routes into other people's lives that can produce both a record of the research encounter as it happened, actions as they were performed and experienced, and spoken and embodied narratives" (Pink, 2005; p277).

The study was conducted by one investigator across the 3 sample sites from May to August 2012 with visits to households lasting approximately $1.5-2$ hours. The study was conducted in 6 households in the UK and India and 7 in Brazil (19 in total).

Participants for the intensive study were young, middle income consumers. Research on consumer segmentation is generally limited, particularly in emerging markets (Schäfer et al., 2011) and little cross-country comparisons exist. Table 2 highlights the consumer groups that were identified in each country and the characteristics associated with each group.

Table 2 Sample Selection Criteria

\begin{tabular}{|c|c|c|}
\hline Brazil & India & UK \\
\hline $\begin{array}{l}\cdot \text {-Class C (SAE Survey) } \\
\cdot \text { Household monthly income } \\
\mathrm{R} \$ 1100-\mathrm{R} \$ 4500 \text { (approx. } \\
£ 300-£ 1300 \text { ) } \\
\cdot 80 \% \text { with access to internet } \\
\cdot 46 \% \text { of all Brazil's } \\
\text { purchasing power } \\
\text { •Higher level of schooling } \\
\text { than parents } \\
\text { - Proportionately younger } \\
\text { than other sectors }\end{array}$ & $\begin{array}{l}\text {-Annual Income Rs } 3.4 \text { lakh } \\
\text { to Rs } 17 \text { lakh (approx. } £ 3500 \\
\text { - £18000) } \\
\text { - Some formal education } \\
\text { - Fastest growing sector } \\
\text { - Spending on durable goods } \\
\text { (Economic Times, 2011) }\end{array}$ & $\begin{array}{l}\text { - NRS BC1C2 } \\
\text { - Intermediate level jobs, } \\
\text { professionals } \\
\text { - Majority of population in } \\
\text { this category } \\
\text { - Average annual household } \\
\text { income between } £ 25,000 \text { - } \\
£ 50,000 \\
\text { - Usually some form of } \\
\text { higher education } \\
\text { - Spending on durable goods } \\
95 \\
\text { - Fastest growing: } 30 \% \\
\text { growth in last decade } \\
\text { (Secom. 2011) }\end{array}$ \\
\hline
\end{tabular}

Participants were chosen from these groups of society as they are a large consumer of modern household appliances, with an available disposable income and an ability or desire to change consumption habits based on societal norms/cues. Tables 3, 4 and 5 show the characteristics for the participants involved in the data collection. 
Table 3: UK Participants

\begin{tabular}{|c|c|c|c|c|c|c|}
\hline & UK01 & UK02 & UK03 & UK04 & UK05 & UK06 \\
\hline Gender & F & $F$ & $M$ & $F$ & $M$ & $M$ \\
\hline Age & $30-35$ & $30-35$ & $20-25$ & $25-30$ & $25-30$ & $30-35$ \\
\hline $\begin{array}{l}\text { Household } \\
\text { members }\end{array}$ & 2 & $\begin{array}{l}2 \text { adults, } 2 \\
\text { children }\end{array}$ & 2 & 4 & 2 & $\begin{array}{l}2 \text { adults, } 1 \\
\text { child }\end{array}$ \\
\hline Occupation & Administration & Researcher & $\begin{array}{l}\text { PhD } \\
\text { Student }\end{array}$ & $\begin{array}{l}\text { Sports } \\
\text { coach }\end{array}$ & Engineer & Marketing \\
\hline $\begin{array}{l}\text { Washing } \\
\text { machine } \\
\text { type }\end{array}$ & Front Load & Front Load & Front Load & Front Load & Front Load & Front Load \\
\hline
\end{tabular}

Table 4: Indian Participants

\begin{tabular}{|c|c|c|c|c|c|c|}
\hline & IN01 & IN02 & IN03 & IN04 & IN05 & IN06 \\
\hline Gender & M & M & $F$ & M & F & $F$ \\
\hline Age & $35-40$ & $30-35$ & $30-35$ & $25-30$ & $35-40$ & $30-35$ \\
\hline $\begin{array}{l}\text { Household } \\
\text { members }\end{array}$ & 2 & $\begin{array}{l}2 \text { adults, } 1 \\
\text { child }\end{array}$ & 2 adults, 1 child & 2 & $\begin{array}{c}2 \text { adults, } 2 \\
\text { children }\end{array}$ & 2 \\
\hline Occupation & Journalist & Engineer & Administration & Architect & Housewife & Translator \\
\hline $\begin{array}{l}\text { Washing } \\
\text { machine } \\
\text { type }\end{array}$ & Front Load & Top Load & Front Load & Front Load & Front Load & Top Load \\
\hline
\end{tabular}

Table 5: Brazilian Participants

\begin{tabular}{|c|c|c|c|c|c|c|c|}
\hline & BR01 & BR02 & BR03 & BR04 & BR05 & BR06 & BR07 \\
\hline Gender & M & $\mathbf{F}$ & M & F & $F$ & $F$ & $\mathbf{F}$ \\
\hline Age & $25-30$ & $30-35$ & $20-25$ & $30-35$ & $20-25$ & $30-35$ & $25-30$ \\
\hline $\begin{array}{l}\text { Household } \\
\text { members }\end{array}$ & 3 & $\begin{array}{l}2 \text { adults, } 1 \\
\text { child }\end{array}$ & 3 & 2 adults & 1 & $\begin{array}{l}2 \text { adults, } 1 \\
\text { child }\end{array}$ & 3 \\
\hline Occupation & Banking & $\begin{array}{l}\text { Masters } \\
\text { Student }\end{array}$ & Accounting & Lawyer & Copyrighter & $\begin{array}{l}\text { Shop } \\
\text { owner }\end{array}$ & Admin \\
\hline $\begin{array}{l}\text { Washing } \\
\text { machine } \\
\text { type }\end{array}$ & Top Load & Top Load & Top Load & Top Load & Top Load & Top Load & $\begin{array}{l}\text { Front } \\
\text { Load }\end{array}$ \\
\hline
\end{tabular}

The analysis of the research took on a theoretical thematic analysis whereby codes were originally focussed on relevant themes identified in previous research, predominantly by Shove (2003). These themes provided a useful base to build upon by using prior research to expand and progress the study area (Shove, 2003; Braun \& Clarke, 2006). In some instances data were coded on a semantic level, dealing with the obvious description of the activity undertaken, purely at a surface level. However, further coding and analysis at a latent level went beyond the surface to identify underlying ideas and assumptions creating themes that are not just descriptive, but already theorised (Braun \& Clarke, 2006).

\section{Results}

In this section the findings from the study into laundry behaviours in Curitiba, Bangalore and 
the East Midlands are presented using the themes of how to launder, exceptions to the routine, time, consumption, perceptions, aspirations, energy and the environment, the climate, and experience.

\subsection{How to launder}

One of the key themes from previous research and one of Shove's (2003) 5 whirlpools of laundry is the technique of how people do the laundry. In Brazil the majority of participants dried their clothes on drying racks in the laundry room, although there was a common dislike to drying clothes when it was cold or humid because it took longer to dry - often laundry was delayed because of this. Similarly in India washing would be less frequent in the wetter months of the year because it takes longer to dry. In the UK $50 \%$ of participants dried their clothes outside because it was free and the clothes smelt better, whilst the other half did not dry their clothes outside because they could not rely on the weather.

Within the Brazilian sample, the most common time to do the laundry was at the weekend as this was when they had the most free time - sometimes washing two batches if necessary. In the UK and India there was no set time amongst participants specifically for laundry. This does, however, tie in considerably with home help. In India all households had home help that came at least once per week, but often for a few hours each day. They would help with the household chores, especially laundry. In Brazil, home help was prevalent in all households, however to a lesser degree - often once every week or fortnight. In the UK, none of the participants had any form of home help. In Brazil and the UK users complained that they were not sure if the detergent mark on the machine was for liquid detergent or powder detergent.

One of the biggest differences across the regions was the built environment. All of the Brazilian participants had some form of laundry room; either a large room off the kitchen or a small separated area on the end of the kitchen. They were deemed important by the participants, particularly for drying clothes where space in the apartment is tight. In India, washing machines were located in different areas around the house, either on the roof terrace (near to drying facilities) or in bathrooms. In the UK, all washing machines were located in the kitchen under the worktop.

\subsection{Exceptions to the routine}

The most common change to the laundry routine across the regions would be if visitors were coming to stay. In India it was common for family to come and stay for prolonged periods of time, which would increase the frequency of laundry from 2-3 times per week to almost daily. 
Other factors that affected the routine would be going away (often for work purposes) and a change of lifestyle e.g. more sport or cycling to work.

\subsection{Time}

As a subtheme of Shove's (2003) 'when to launder' theme, the perception of time equates to an important factor to consider in the design of new products and services. In Brazil, there were three noticeable types of washing technique related to time; those that washed on the quickest setting because they wanted it as soon as possible; those that put it on the longest setting to clean the clothes more thoroughly; and those who were not bothered about time, putting the washing in and returning hours later to collect it. In India, the participants generally used the quickest wash setting, and in the UK, participants either used the quick wash or were not bothered about time.

\subsection{Consumption}

With the participants in the more intensive study, consumption patterns were focussed around the price and brand of the product, often recommended by other people and past experiences. Regarding the laundry, Brazilian and Indian participants bought the machine based on price, brand and energy rating; whilst the UK sample were less affected by brand or energy label, buying predominantly the cheapest machine. In many cases in the UK, the participants using the machine were not the original purchasers of the machine. This significantly affects the 'tools' used in the laundry process, with cultural variations having an influence over both the design and consequently the energy impact of the laundry process.

Generally speaking purchasing decisions were made based on previous experience, with a particular product getting re-purchased if it was available at a reasonable price and had performed its function to a satisfactory degree. This largely correlates with habit formation, with consumers sticking to a brand that they know works well especially if there is no specific reason to change. A change in purchasing decision would occur when the consumer was unhappy with the performance or believed an alternative was better based on their perceptions e.g. changing machine from vertical axis to horizontal axis.

"The brand is good and it works just fine for me" (BR01).

\subsection{Perceptions}

An important theme, significant to 'why' the laundry is done, is the perceptions related to the various processes involved in the laundry process. In Brazil and India, despite vertical axis machines being common, the perception by all-bar-one participant was that horizontal 
machines are better. There is little understanding as to why this might be the case, with little justification for the view point other than "I just heard that it's better" (BR03).

Perception of dirtiness was a factor that was varied between the samples in the different regions. One Brazilian participant always used the longest washing setting on the machine as she believed the other settings were not long enough to clean the clothes thoroughly. In contrast, a couple of Indian participants used the shortest setting because they believed the machine washed clothes to an unnecessary degree. The UK sample showed participants with both of these views.

The influence of other people was also a key factor in laundry behaviour. There were strong indications that participants were affected by their upbringing (particularly how mothers did the laundry), what the people around them did, and what was the perception of the larger region or country. Participants in all regions pointed to recommendations from friends for consumption decisions such as type of machine and detergent, whilst mother's had strong influences over washing technique. Often, participants took behaviours from their mothers but changed them to fit their own contexts, often relating to their mother's 'better' technique

"I can never get them smelling as good as my Mum" (UK05).

Generally, laundry was a deeply habitual behaviour with people just doing it because they had to and the way they were doing it was working just fine. Behaviour would only change if there was a problem.

\subsection{Aspirations}

In Brazil, despite vertical axis machines being by far the most common, nearly all participants wanted to own a horizontal axis machine. The common perception was that horizontal axis machines clean clothes better, are more water efficient and take up less space. However they were deemed expensive and of poor build quality in Brazil. The participants also preferred the fact that with vertical axis machines, garments could be added half way through a wash if they had forgotten to put something in. Many Brazilian participants also wanted to wash clothes in warm water due to a perceived better cleaning ability, particularly for whites and stains, however were concerned with the cost of the initial outlay for the machine and the cost of running it.

Most Indian participants were happy with their machines apart from those with vertical axis machines who wanted to change to horizontal axis.

\subsection{Energy and Environment}


In Brazil and India, participants actively sought to buy a machine that was ' $A$ ' rated on their respective appliance energy rating scales. However they did not think the washing machine was a particularly high consumer of energy in the household and therefore, after the initial purchase of an energy efficient machine, did not think there was anything else in their power to reduce consumption.

Participants in both Brazil and India were more concerned with the water efficiency of washing machines than the energy input. In Brazil, many participants monitored closely the amount of water they filled their vertical axis machine with. In contrast, the UK sample was more concerned with the energy of the appliance than the water consumption; however few participants changed their behaviour to save energy. Mostly, UK participants were concerned about the high energy consumption of the tumble dryer and in general tried not to use it too often.

\subsection{Climate}

A new theme based on the external environment and not obviously portrayed in the prior theory or Shove's 5 whirlpools of laundering (2003), is the climate. The weather played a major role in when the washing was done in all three regions. In all regions the majority of participants stated that they washed more in summer due to sweating more and changing clothes more often. Participants reacted differently to the need to wash with one Brazilian participant scrubbing clothes by hand in summer to remove all sweat, whereas one Indian participant suggested they only rinse clothes quickly as they do not consider them to be too dirty. Indian participants also suggested they washed more in summer due to the increased prevalence of dirt and dust on the street.

\subsection{Experience}

Previous experience was one of the main reasons for consumption patterns, particularly seen in the Indian participants. Participants either bought the same style of machine due to a positive past experience, or changed the machine due to negative past experiences. This was also true with washing in hot water, with participants suggesting that they had never used hot water before so could not be sure of the benefits. In this instance past experience could be overcome by the introduction of perceived benefits, as in the case of some Brazilian participants who wanted hot water washing for its perceived benefits.

In most cases, current laundry behaviour was built up by previous experience with changes often occurring because of a shock negative result. One Brazilian participant suggested she learnt more about the washing process and her machine after she shrunk a jumper that she 
particularly liked, whilst a UK participant understood the correct filling amount based on previous experience and machine functionality:

"I try not to shove too much in, 'cos then it doesn't spin very well." (UK'02)

\section{Discussion}

The results from the study offer insights into a number of challenges and opportunities for designers by identifying factors that can help shape behaviour. Some factors relate to personal behaviours affected by independent elements, whilst other factors can be affected by the physical and social contextual environment. These factors are outlined in more detail below.

\subsection{Cultural Significance vs. Cultural Independence}

The analysis of the washing process in the three regions has highlighted elements of the process that are 'culturally significant' and elements that are 'culturally independent'. Cultural significance refers to the elements of the washing process that were common amongst the samples in their respective regions; often contextual factors at a macro level. Culturally independent elements refer to the differences between the individuals throughout the samples; often influenced by perceptions or experience. The following section explains these terms in more depth.

\subsubsection{Culturally Significant Elements}

Culturally significant elements identified included; the external environment, the influence of other people, consumption, tools, and inputs.

One key element that affected each sample group as a whole was the external environment. This typically can be divided further into physical elements; the climate, and human elements; the built environment.

The climate is one of the main culturally significant factors that influenced the laundry behaviours in all three regions. Climate is a factor beyond human control that differs significantly from region to region. As a result, it influences people to behave in different ways as they interact and overcome the challenges it may throw at them at either end of the scale. In the samples, participants' altered the laundry behaviour based on the climate. Laundry was often delayed on days where it would be difficult to dry outside, or on occasion the tumble dryer would be used. This is a clear factor that designers need to account for when developing products and services for different markets as a simple translation from one context to another may be irrelevant to that region; for example the lack of need or 
desire for tumble dryers in the Indian sample due to more reliable weather.

The other main influence of the external environment is the built environment. This refers to the area where a user lives and the affect that it can have on behaviours. In the laundry example, the sample shows us that it is common place for Brazilian households to have a 'laundry room'. This is often a designated room off to the side of the kitchen which contains the laundry machine, a sink and washboard, a cupboard with all the washing tools and utensils, and drying facilities. This single observation has a relevance on the laundry process between the three regions, however also builds on important information that designers need to be aware of. The infrastructure, type of house, building materials, layout etc. all play a significant role in routines around the house and their resource implications and therefore should be investigated by designers when creating products for different markets.

In India, participants altered their laundry behaviour due to the dust and dirt on the street, and this changed seasonally.

The Influence of other people also has a bearing on the particular process being examined. In the case of laundry, the prevalence of home-help is something that varies in each region and affects the laundry procedure. In India and Brazil having home-help either daily or weekly is common, with the maid often asked to wash clothes, whilst in the UK this is not common.

Another important culturally significant element is consumption in the macro sense. Consumption encompasses the price, marketing and costs (e.g. energy payments) within a region and is closely linked to average income. We can assume that the price of energy or water within a particular region will have an effect on the end user behaviour and thus the consumption of utilities is culturally significant. In the same way the marketing of a particular brand of detergent or machine will be different between regions, we can also look at average income and price of goods as factors that will differ culturally. Another area that will affect consumption is the implementation of any incentives or feedback schemes such as energy rating scales on washing machines.

Closely linked to consumption are the tools involved in the process. These are the instruments and artefacts used by the people in a selected group or region. Whilst the specific tool, for example brand of washing machine, may vary between individuals within a region, the overarching type or technology may be culturally significant. In this case we can look at the top loading machine being by far the most common type of machine in Brazil compared to the front loading machine in the UK, as well as the use of heated water in the UK compared to cold water in India and Brazil. This link to new technologies can significantly 
reduce the environmental impact of the behaviour. Previous research by Laitala et al. (2011) suggested that, with modern day detergents, washing at $30^{\circ} \mathrm{C}$ was just as effective and prolonged the life of clothing than washing at $40^{\circ} \mathrm{C}$.

As a sub category of the tools of laundering we can also look at the inputs into the tool; in this case, the clothes that are being laundered. These differ from region to region in terms of the materials and dyes used and the fashion of particular areas affect how and when the laundry is done.

\subsubsection{Culturally Independent Elements}

Culturally independent elements identified included; perceptions, aspirations, senses, views, and income.

Culturally independent elements are those factors that are not representative of a region; they are based on an individual's perceptions and behaviours and may be shared by people from different regions or groups. Interestingly the previous significant factors (external environment, other people, consumption, tools and inputs) may all have had an input in shaping the independent elements of an individual, but with greatly different results in each case. This is explained in more detail below.

A large part of the independent elements are made up by people's perceptions. These may be a perception of cleanliness or dirtiness, the perception of a brand, perception of effectiveness or perception of the process. An example would be the increased frequency of a wash between two participants because one perceived a garment to be dirtier than the other participant. The two participants might be from the same region, or from completely different areas or cultural contexts. These perceptions are predominantly built up by a wide variety of influences, namely; past experiences, upbringing, recommendations/observations of others, income; as well as the significant elements above; external environment, other people, consumption, tools and inputs. Ultimately these perceptions will change the way users behave, but will differ according to the individual.

Closely linked to perceptions and another independent factor influencing behaviour is aspirations. Similar to perceptions, aspirations are influenced by all the same factors; however, they deal with what the participant would rather have or aspire to do/have/behave. As an example we could look at the Brazilian participants who owned a vertical axis machine but aspired to own a horizontal axis machine because of the perceived benefits it would bring.

Senses are also a major factor that makes up culturally independent elements. Participant's 
sense of smell, touch and sight, and the meanings they attributed to them, differed vastly between participants. Equally participant's views, such as their environmental views, played a huge factor in their behaviour and interaction with artefacts, which largely could not be attributed to a culture, context or region. Income was also an independent factor as this differs between households.

By identifying the elements that are common amongst a group of people and those which are independent we can start to understand how best to influence users' behaviour. We can begin to group individuals based on their washing technique and the factors that have influenced this technique, whilst we can also look at the significant elements of a region that can help us to design more appropriate products for an area.

The culturally significant elements offer us insights as to what we understand are the shared beliefs and behaviours of a group of people, whilst the culturally independent elements are beyond those boundaries; beliefs and behaviours that are independent of cultural context. Understanding this link between the two entities governs how culture can really affect design. The factors introduced above give designers tangible elements to take into account when designing that tie into cultural dimensions and the social and individual choice models of behavioural theory.

\subsection{Design Guidelines}

The cultural factors identified above can help designers to build empathy within a particular context and therefore better identify behaviours that can be designed for. This, however, is only the first part of the challenge. The following 7 guidelines have also been created from the research which can help moderate more sustainable behaviour.

The 7 guidelines are a direct consequence of the research in the three contexts. Some of the guidelines may be familiar from other aspects of design or behaviour research, such as 'emotional durability' by Chapman (2005), putting the user in control, or making the waste visible by Lilley (2007). Due to their origins, the guidelines relate specifically to the laundry process, however, can provide concepts that can be transferred to other resource intensive household behaviours. Below the guidelines are listed with examples in each case to aid designers in the ideation process for products to reduce resource impacts during use.

\section{1) Understand the flow of the procedure from start to finish. Understand the various} 'touch points' in the system.

(How does the laundry make its way around the house? Who, what, where \& when?) 


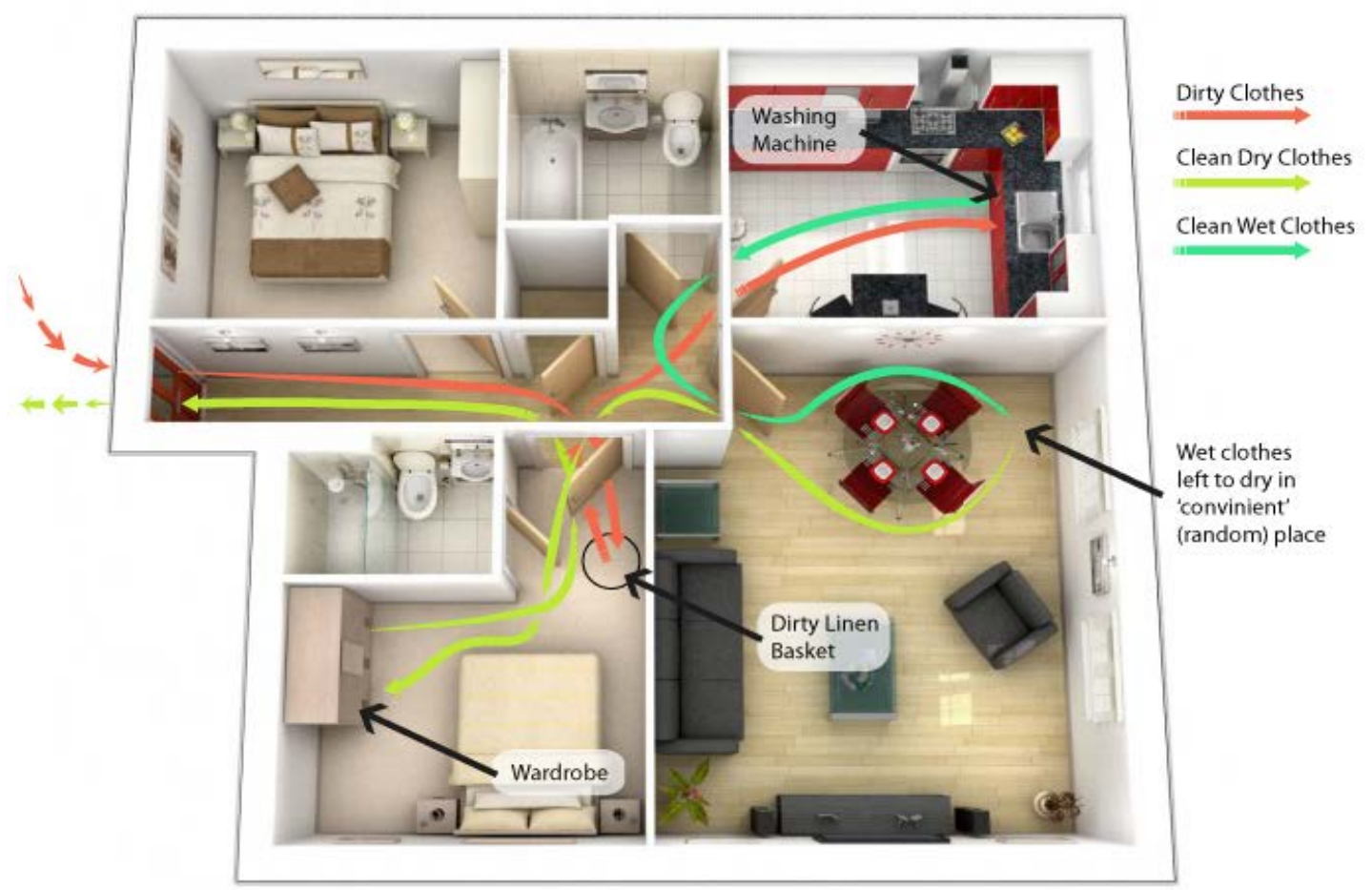

Figure 2: Simplified journey of clothing for one user (UK)

Figure 2 shows the simplified journey of clothing for one user around a typical home in the UK. The journey is simplified as, in reality; individual users will have very different routines.

In Brazil, most apartments have an 'area do serviço' (service area) specifically for the laundry where clothes are washed \& dried (and ironed if needed). The journey of the laundry takes a simplified route (Figure 3). Understanding the user journey for household behaviours helps designers create more relevant and engaging products and potentially opens possibilities for sustainable innovation in areas they might not have thought of, had they been concentrating on one artefact. For example, if a designer has been tasked with designing a new washing machine, understanding the entire user journey for the laundry process is a useful exercise, rather than just investigating one point of interaction with the machine. Learning about the entire journey can drive sustainable behaviour by leading to contextual insights on climate and infrastructure and thus developing innovations in reducing drying time, taking inspiration from the Brazilian service area for example and reducing energy intensive drying behaviours, as in Table 1. 


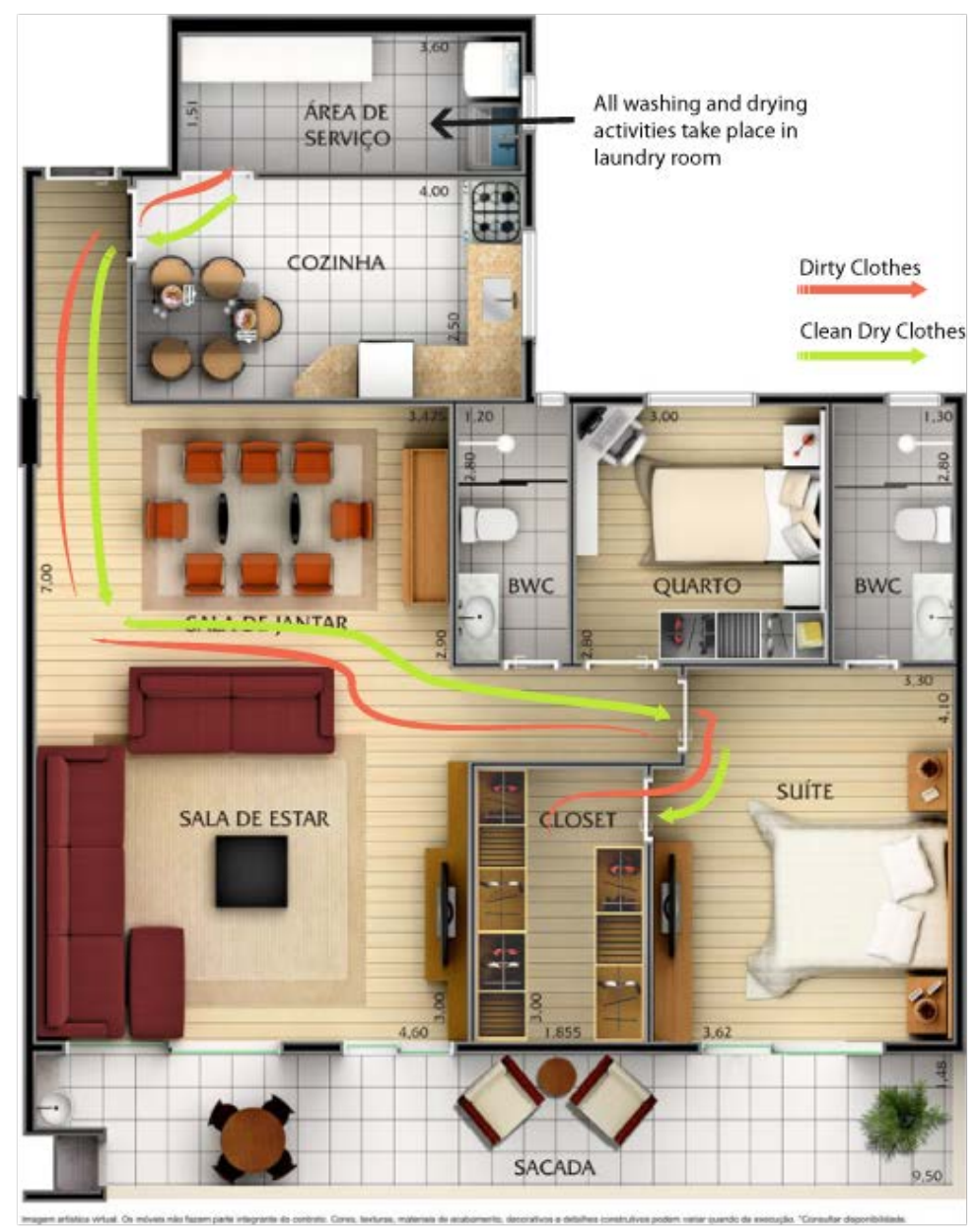

Figure 3: Typical Brazilian Apartment with Service Area

\section{2) Integrate the design of the procedure with the design of the spaces where the procedure occurs}

(Can the process be linked with other processes (killing 2 birds with one stone)? Can there be a better use of space in the household?)

In India, some modern houses are designed to accommodate the washing machine on the roof terrace so that waste water can be filtered down through the house to other appliances or to water the plants in the garden (Figure 4). By understanding the space, designers can steer users towards more sustainable behaviours from Table 1 such as minimising waste or re-using the resource in other applications - a process influencing behaviour through 'scripting' as described in the behavioural model of Wever et al. (2008). 


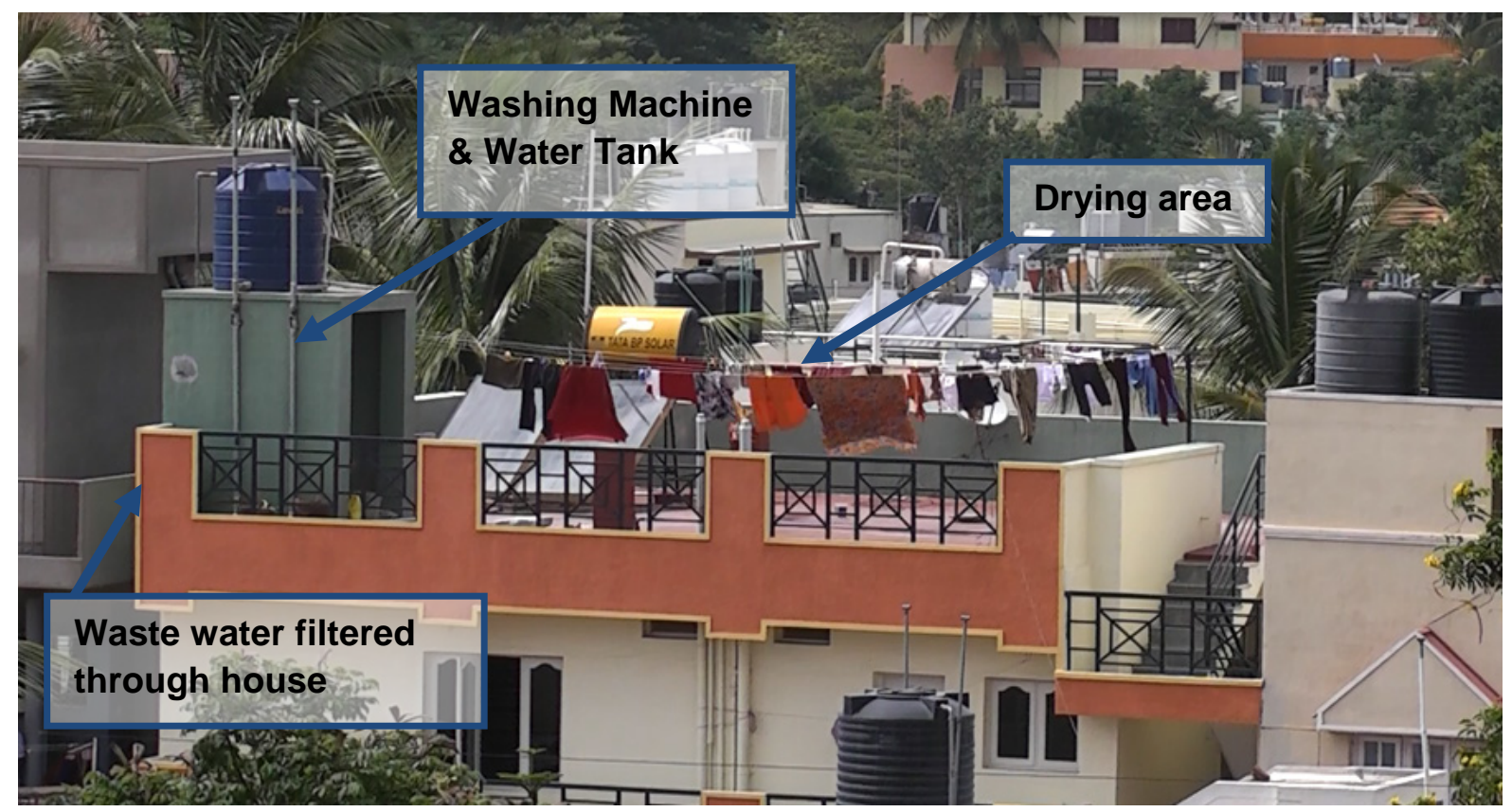

Figure 4: Example of Laundry Space in India

\section{3) Adapt the design to suit the needs of the user}

(Is the user a 'time related' washer or a 'sense related' washer? Do they use the different programs or not?)

Lilley's behavioural model (2009) suggests a scale with technology dictating product use at one end. This guideline suggests the use of intelligent design where the technology adapts depending on the use of the product and draws influence from functionality matching of Wever et al.'s model (2008). In all three contexts, users fell into one of 2 categories; those that chose the cycle based on the time it took, and those that chose the cycle based on the most appropriate setting and senses such as smell. An intelligent design would learn if a user washed based on senses and changed the wash cycle to accommodate this. This drives sustainable behaviour by controlling the resource input and making the process the most efficient for the desired outcome. For example, a user may wash using the quickest setting on the machine, believing this to use the least energy, when in reality it may heat the water and use considerably more than an alternative setting.

\section{4) Give the user control to influence the resource use of a process}

(Is the user in control of the amount of energy and water used? Can the user add garments half-way through? Can the user choose the exact programs they desire?)

In Brazil, it was noted that the advantage of a vertical axis machine was to be able to add garments that had been forgotten half way through the wash. Vertical axis machines also give the user control by letting them manage the amount of water in the machine. Whilst the common aspiration was to have a horizontal axis machine, some of the control elements in a 
vertical axis machine could be transferred. This builds on the axis of control outlined by Lilley (2009) in which the designer has the ability to put the user in control or the technology in control of the desired behaviour. This matches the conclusion of Zachrisson et al. (2011), who state the more control a user has the more cognitive load the behaviour requires. As Table 1 in the literature suggests, giving the user control reduces the resource inputs into the system.

\section{5) Create a new emotional attachment between the user and the process}

(Does the user enjoy the process or hate the process? What would make them enjoy it more?)

Laundry will always be a chore; however importance should be given to making the process more enjoyable (not necessarily just easier!). Are there other connotations and stimuli that can be evoked by doing the laundry, for example, circulating the 'freshness' smell of laundry around the house to evoke positive sensory connotations. By engaging the user emotionally, they are more likely to use the product in the desired way or change their behaviour to a desired action, in this case a more sustainable behaviour, such as washing less frequently or using a natural detergent (Table 1). Of course, emotional satisfaction with product use could lead to over use or more frequent wash cycles, something which the designer should consider - to ensure emotion is only targeted in a way to promote sustainable behaviour. At the very least, an emotional attachment between user and product will place more value on the relationship and decrease the rate of replacement and product obsolescence, a concept coined 'emotionally durable design' by Chapman (2005). There are also connotations for engagement based on social norms, by reducing product obsolescence and building an emotional attachment becoming the norm in society as people prefer to fit into a social order, as identified by social theories e.g. Wilk (2002) in the literature.

\section{6) Let the user know and understand the various resource inputs and outputs of the process}

(Can the user see the various inputs/outputs? - Make the user aware of the resource use)

In Brazil, free standing washing machines have to be installed by the user. Water is added in a visible way by the user where they have to attach the machine to the tap and turn it on, whilst watching the machine fill up to the desired level. Waste water from the machine then passes through a pipe that is placed in the sink. Users understand the inputs and outputs to the system and can see the waste (Figure 5). By visually engaging the user, the product motivates the user to use less water. In this way, users are empowered to change to more sustainable behaviour by giving feedback on their actions, providing a feeling of competence of change and making the impact of their behaviours tangible (Heiskanen et al., 2010). 


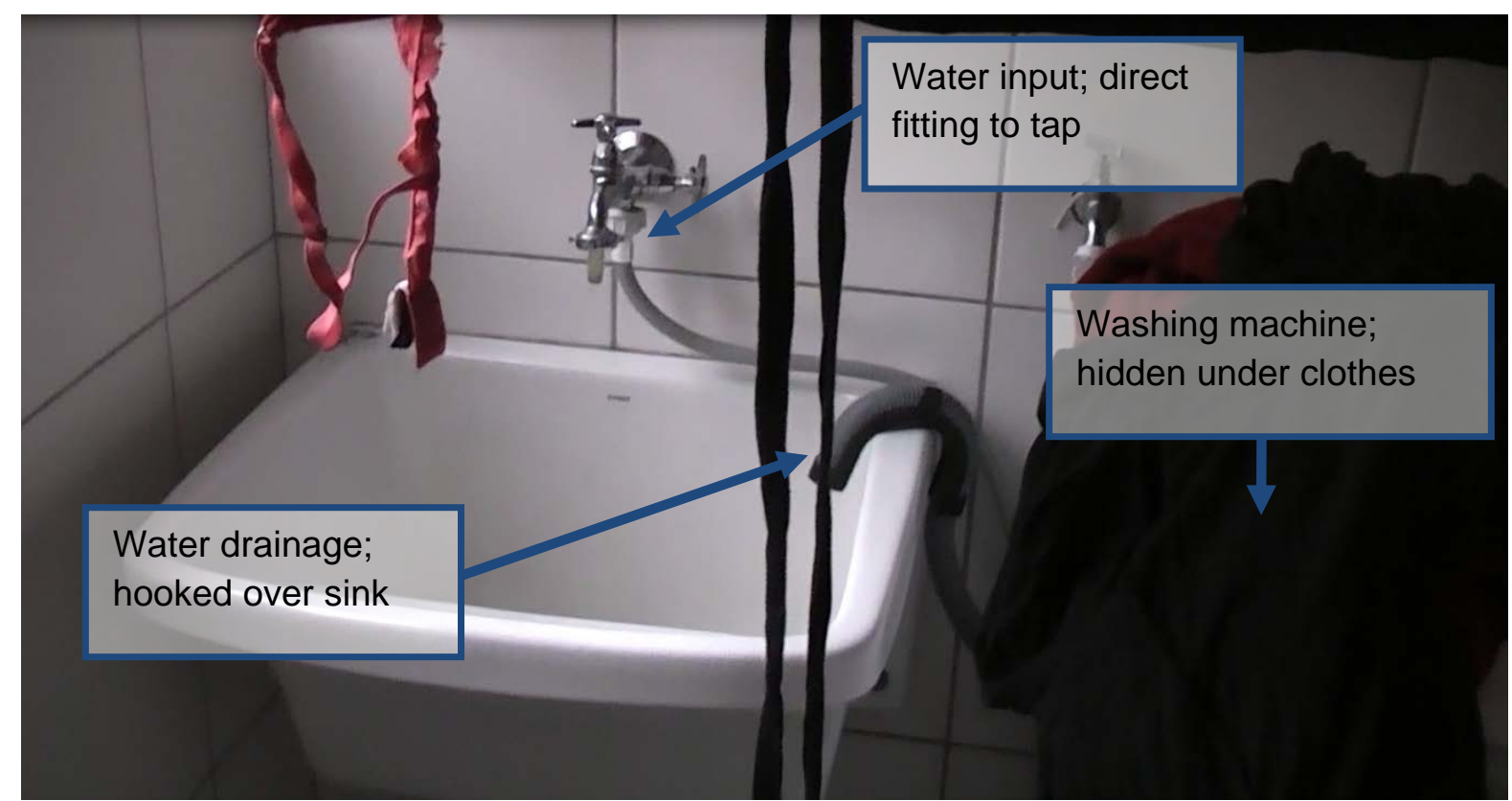

Figure 5: Understanding the Resource Use - Brazil

7) Be clear about the operation of the process. Give the correct and relevant information at the right time, in the right place.

(Is there a clear indication of how much detergent or water or energy to put in?)

Real time aural or visual feedback can promote sustainable behaviours by avoiding misuse or confusion (Lilley, 2009). Labelling products as 'A energy rated' implies to the user that they have done everything in their power to lower their resource impact, when in reality, it might not be best suited for their needs or identified behaviours. For example, a consumer may buy an ' $A$ ' energy rated tumble dryer to dry their clothes, when in reality, altering their routine or their environment may mean they can dry their clothes naturally, using no energy at all.

\section{Conclusions}

The research aimed to understand the opportunities that different cultural contexts can create for sustainable design, using laundry as an example to understand the complexities of everyday household behaviours. The identification of the various significant and independent cultural factors allows designers to build empathy within a context and helps understand the key areas that can be designed for when thinking about a new process; whilst the guidelines can suggest possible routes to creating solutions with desired behaviours (Figure 6). 


\begin{tabular}{|l|l|l|}
\hline $\begin{array}{l}\text { UNDERSTANDING THE } \\
\text { CONTEXT }\end{array}$ & GUIDING CHANGE & DESIRED BEHAVIOURS \\
\hline $\begin{array}{l}\text { Culturally Significant / } \\
\text { Independent factors }\end{array}$ & & $\begin{array}{l}\text { Sustainable laundry } \\
\text { behaviours }\end{array}$ \\
\hline
\end{tabular}

Figure 6: Using the Resources developed

Figure 6 illustrates how the research can be used by designers looking to transfer behaviours between contexts. In this case the unfamiliar context can be understood by applying the cultural factors to research in the area. They provide not only a resource for relevant information to collect, but also which behaviours are susceptible to change and possible influences on these behaviours. The guidelines can then be utilised in the ideation and development process to affect changes to the design that will moderate behaviour. Transferring behaviours between contexts may be possible if the various cultural factors can be aligned or designed to accommodate new contexts. For example, making the water use visible to users in the UK, as it is with participants in Brazil, may not mean introducing top loading machines into the area, but rather a subtle design feature that that allows the user to visualise the water use may be more suitable. The research is therefore not only relevant to laundry care design, but to a range of cross-cultural household behaviours. One example where the research could be utilised would be domestic thermal comfort, whereby researching culturally significant and independent factors will lead to ideation and inspiration for the transfer of less resource intensive behaviours in new heating and cooling systems in different contexts.

Both the cultural factors and the design guidelines have been identified based on the current study area of laundry behaviours within the household in three contexts; Curitiba, Brazil; Bangalore, India; and Loughborough, UK. Neither is therefore an exhaustive list that can be used in all contexts for all behaviours; however both can be used as a platform to develop and further understand other aspects of cross-cultural behaviour in wider contexts.

The idea behind the above tools is not to give designers a rigid framework to adhere to, as by its definition, design is a fluid and flexible creative process; however the resources can assist in designing in cross-cultural contexts by providing themes to better identify with the user in a given context and guidelines to aid changes to predetermined desirable behaviours.

In this research the importance of empathy has been built upon by identifying cultural factors 
that the designer can use to understand an unfamiliar context, whilst the guidelines enable the designer to affect changes, building on the research gaps identified in the introduction. The resources developed within this research are linked to theories of behaviour and culture, typically used in organisational or business theory, such as Hofstede's cultural dimensions (1980). Moving Hofstede's cultural dimensions from business communication to the design process is one way to engage with new markets. The implementation of Hofstede's dimensions, along with the resources developed in this research can assist in the ideation and evaluation of a design in a particular context. Designing solutions, such as community based washing systems, will not have the same impact in individualistic societies as in collectivist societies, which designers should be aware of. The research has shown that, with the right resources, designers can make use of cultural factors to innovate and create products for different cultural contexts. As well as a theoretical contribution of the impact of cultural contexts for designers, the process of doing the research has also contributed to new knowledge on household, and specifically, laundry behaviours of users in the UK, Brazil and India; a field typically dominated by quantitative technical testing in Europe and Japan.

\subsection{Limitations and Further Study}

Whilst the research contributes to the embryonic field of culture and design for sustainable behaviour, there are several limitations to conducting a global study of this kind. Generous grants from Santander and the Design Research Society allowed the research trips to be conducted in Brazil and India, however these were one-time only trips, and therefore data collection had to be curtailed to fit within the single visit. Using video and contextual immersion helped to alleviate some of the limitations of a single visit, however further studies could involve more prolonged research with participants and a greater number of participants from various socio-economic groups within the same region, to see if similar results would be found. The study was also conducted with small samples that could not be considered representative and therefore the guidelines are limited to the sample groups that were studied. It would therefore be beneficial to test the resources developed for other design for sustainable behaviour challenges, in other household areas such as lighting or heating.

\section{Acknowledgments}

Many thanks to Santander and the Design Research Society for supplying the funding for the research trips to Brazil and India. Thanks also to Professor Aguinaldo dos Santos of UFPR in Curitiba, Brazil and Chitra Vishwanath of Biome Architects in Bangalore, India for helping to facilitate the data collection. Thanks to all the participants for giving up their time for the research. 


\section{References}

Abrahamse, W., Steg, L., Vlek, C. \& Rothengatter, T. 2005. A review of intervention studies aimed at household energy conservation. Journal of Environmental Psychology, 25, 273291.

Banks, J.A. \& McGee. 1989. Multicultural Education. Needham Heights, MA, Allyn \& Bacon.

Braun, V. \& Clarke, V. 2006. Using Thematic Analysis in Psychology. Qualitative Research in Psychology, 3, 77-101.

Chapman, J. 2005. Emotionally Durable Design: Objects, Experiences and Empathy. London: Earthscan Publishing.

Chau, P.Y.K., Cole, M., Massey, A.P., Montoya-Weiss, M. \& O'keef, R.M., 2002. Cultural differences in the online behavior of consumers. Communications of the ACM, 45, 138- 143.

Elizondo, G. 2012. Designing for sustainable behaviour in cross-cultural contexts: a design framework. Design School. Loughborough University.

Environmental Change Institute. 2005. 40\% House, Oxford, Oxford University.

Euromonitor International. 2011. Home laundry appliances in India. Available at: http://www.euromonitor.com/home-laundry-appliances-in-india/report. Accessed: April 2012.

Geertz, C. 1973. The Interpretation of Cultures. Basic Books, New York.

Gill, Z. M., Tierney, M. J., Pegg, I. M. and Allan, N. 2010. Low-energy dwellings: the contributions of behaviours to actual performance. Building and Research Information, 38(5): 491-508.

Global Footprint Network. 2010. Living Planet Report 2010. WWF International, Switzerland.

Goldsmith, E.B. \& Goldsmith, R.E. 2011. Social influence and sustainability in households. International Journal of Consumer Studies, 35, 117-121.

Green, K. \& Vergragt, P. 2002. Towards sustainable households: a methodology for developing sustainable technological and social innovations. Futures 2002;34:381e400.

Greendex. 2010. Greendex: Survey of Sustainable Consumption. National Geo-graphic. Available at: http://environment.nationalgeographic.com/environment/greendex/. Accessed: 10/12/10.

Guðjónsdóttir, R. \& Lindquist, S. 2008. Personas and scenarios: Design tool or a communication device? In Proceedings of COOP'08, Carry Le Rouet, France, pp. 165-176.

Haines, V., Mitchell, V. \& Mallaband, B. 2012. Merging a Practice-Orientated Approach with an Engineering-driven Product Development: a Case Study on Home Improvement. Journal of Design Research, 10, 50-66. 
Haratty, M., Bhamra, T., \& Mitchell, M. 2012. Digital Design for Sustainable Behaviour: A conceptual framework to guide design intervention. Proceedings of BCS $\mathrm{HCl} 2012$ Workshops Using Technology to Facilitate Behaviour Change and Support Healthy, Sustainable Living. Available at: http://ewic.bcs.org/upload/pdf/ewic_hci12_sl_paper5.pdf [Accessed: April 2013].

Heiskanen, E., Johnson, M., Robinson, S., Vadovics, E. and Saastamoinen, M. 2010. Lowcarbon communities as a context for individual behavioural change, Energy Policy, doi:10.1016/j.enpol.2009.07.002

Hofstede, G. 1980. Culture's consequences: International differences in work-related values. Beverly Hills, CA: Sage.

Jackson, T. 2009 Prosperity without growth? The transition to a sustainable economy. UK Sustainability Commission, London, UK.

Kroeber, A.L, \& Kluckhohn, C. 1952. Culture: A critical review of concepts and definitions. Harvard University Museum of American Archeology and Ethnology Papers 47.

Kuijer, L. \& De Jong, A. 2009. A Practice Oriented Approach to User Centered Sustainable Design. Ecodesign 2009 Conference. Saporo.

Laitala, K., Boks, C. \& Klepp, I.G. 2011. Potential for environmental improvements in laundering. International Journal of Consumer Studies 35, 254-265. Blackwell Publishing Ltd.

Laitala, K., Klepp, G.I. \& Boks, C. 2012. Changing laundry habits in Norway. International Journal of Consumer Studies. Blackwell Publishing Ltd.

Liamputtong, P. 2010 Performing qualitative cross-cultural research. Cambridge University Press: Cambridge.

Lidman, K.M.E., Renström, S., Karlsson, M.I.C. 2011. The green user. Design for sustainable behaviour, IASDR Conference 2011, Diversity and unity, Delft, the Netherlands, pp. 1-12.

Lilley, D. 2009. Design for sustainable behaviour: strategies and perceptions. Design Studies, 30(6): 704-720.

Lockton, D., Harrison, D. \& Stanton, N. 2008. Making the user more efficient: design for sustainable behaviour. International Journal of Sustainable Engineering, 1(1): 3-8.

Matsuhashi, N., Kuijer, L., \& de Jong, A. 2009. A Culture-Inspired Approach to Gaining Insights for Designing Sustainable Practices. EcoDesign 2009. Japan.

McClelland, I. \& Suri, J. F. 2005. Evaluation of Human Work. Involving people in design. In: Wilson, J. R. \& Corlett, N. (eds.) Evaluation of Human Work. 3 ed.: CRC Press. 
ONS. 2011. Ownership of consumer durables increases into 2010. Available at: http://www.ons.gov.uk/ons/rel/family-spending/family-spending/family-spending-2011edition/sum-consumer-durables-nugget.html. Accessed: April 2012.

Pakula. C \& Stamminger, R. 2010. Electricity and water consumption for laundry washing by washing machine worldwide. Energy Efficiency. Springer Publishing, Netherlands.

Pettersen, I.N. \& Boks, C. 2008. The ethics in balancing control and freedom when engineering solutions for sustainable behavior. International Journal of Sustainable Engineering, 1(4): 287-297.

Pink, S. 2005. Dirty Laundry. Everyday practice, sensory engagement and the constitution of identity. Social Anthropology, 13, 275-290.

Robson, C. 2011. Real World Research. Oxford, Blackwell Publishers Ltd.

Schäfer, M., Jaeger-Erben, M., \& dos Santos, A. 2011. Leapfrogging to sustainable consumption? An explorative survey of consumption habits and orientations in Southern Brazil. Journal of Consumer Policy

Shove, E. 2003. Comfort, Cleanliness and Convenience, Oxford: Berg.

Shove, E. 2006. POPD Manifesto. Durham University.

Smith, F. 1997. Environmental Sustainability. Practical Global Implications. St Lucie Press, Boca Raton, USA.

Spencer, J. \& Lilley, D. 2012. The effect of culture on sustainable behaviour in a design context. Proceedings of 2nd PERL International Conference: Beyond Consumption; Pathways to sustainable living. Technische Universität Berlin.

Steg, L. \& Vlek, C. 2009 Encouraging pro-environmental behaviour: An integrative review and research agenda. Journal of Environmental Psychology, 29, 309-317.

Steg, L. 2008. Promoting household energy conservation. Energy Policy, 36, 4449-4453.

Stern, P. C. 1999 Information, Incentives, and Proenvironmental Consumer Behavior. Journal of Consumer Policy, 22, 461-478.

Tang, T. \& Bhamra, T. 2012. Putting consumers first in design for sustainable behaviour: a case study of reducing environmental impacts of cold appliance use. International Journal of Sustainable Engineering, 5:4, 288-303.

Tang, T. 2010. Towards sustainable use: design behaviour intervention to reduce household environment impact. Design School PhD. Loughborough University

Triandis, H.C. 1980. Values, attitudes and interpersonal behaviour. In: H.E. Howe \& M.M. 
Page, eds. Nebraska symposium on motivation, Lincoln, NE: University of Nebraska Press.

Uitdenbogerd, D.E. 2007. Energy and Households - the Acceptance of Energy Reduction Options in Relation to the Performance and Organisation of Household Activities.

Wageningen University.

Wilhite, H. 1999. Social Loading and Sustainable Consumption. Advances in Consumer Research, Volume 26, pp 281-287.

Wilson, G. T., Bhamra, T. A. \& Lilley, D. 2010 Reducing Domestic Energy Consumption: A User-Centred Design Approach. ERSCP-EMSU 2010, European Roundtable on Sustainable Consumption and Production and Environmental Management for Sustainable Universities (ERSCP-EMSU) 2010 Conference: Knowledge Collaboration \& Learning for Sustainable Innovation. Delft, The Netherlands, Faculty of Industrial Design Engineering, Delft University of Technology.

Wilson, G.T., Lilley, D. and Bhamra, T.A., 2013. Design feedback interventions for household energy consumption reduction. 16th Conference of the European Roundtable on Sustainable Consumption and Production (ERSCP) \& 7th Conference of the Environmental Management for Sustainable Universities (EMSU) (ERSCP-EMSU 2013), Istanbul, Turkey, 4th-7th June 2013.

Wever, R., Van Kuijk, J. \& Boks, C. 2008. User-centred design for sustainable behaviour. International Journal of Sustainable Engineering, 1, 9 - 20.

Zachrisson, J., Storro, G. \& Boks, C. Using a Guide to Select Design Strategies for Behaviour Change; Theory vs. Practice. Proceedings of EcoDesign 2011 International Symposium, 2011 Kyoto, Japan. 